\title{
A ficção seriada e a construção da memória dos universitários pela minissérie JK
}

\author{
Paula Regina Puhl ${ }^{1}$ \\ Cristina Ennes da Silva ${ }^{2}$
}

\begin{abstract}
Resumo: $O$ artigo analisa a construção de uma memória histórica decorrente da audiência da minissérie JK, veiculada pela Rede Globo em janeiro de 2006. Enfocamos aspectos inerentes às fontes de investigação históricas especialmente no que tange as produções audiovisuais, bem como de elementos constitutivos da produção de uma minissérie de temática nacional baseada em acontecimentos históricos, destacando a problemática inerente ao roteiro ficcional. Interessou-se compreender se a ficção baseada na história influenciava na constituição da memória sobre o acontecimento em acadêmicos que, por atuarem nas áreas do conhecimento que envolvem a comunicação e a história apresentavam um certo conjunto de conhecimentos específicos.
\end{abstract}

Palavras-chave: comunicação; minissérie JK; memória; acontecimentos históricos;

\begin{abstract}
This paper analyses the construction of a historical memory from the audience of the JK television miniseries, broadcasted by Globo TV in january 2006. We emphasize aspects intrinsic to the historical research sources, especially in what relates to the audiovisual productions, as well as elements that characterize the production of a national-themed miniseries based upon historical fact, taking into account the problems related to the fictionalization. We were interested in understanding of history-based fiction did influence the constitution of memory about the subject in college students from communication and history schools with a broadly defined set of knowledge related to this theme.
\end{abstract}

Key-words: communication; JK television miniseries; memory.

Résumé: L'article analyse la construction d’une mémoire historique découlante de l'audience du téléfilm JK, véihculé par Rede Globo en janvier 2006. Nous avons détaché des aspects inhérents à des sources d investigation historiques, spécialement des productions audiovisuelles, aussi bien que des élements constituitifs de la production d`un téléfilm tématique national basé sur des événements historiques, en détachant la problématique concernente au script fictional. On a cherché de comprendre si la fiction basée sur l'histoire influenciait dans la constituition de la mémoire sur l'événement par des étudients de l'Histoire et la Communication qui, par rapport a ses activités dans ces deux champs de la connaissance, présentaient un certain ensemble des connaissances spécifiques dans ce sense.

Mot-clef: communication; téléfilm JK; mémoire.

Resumen: El artículo analiza la construcción de una memoria histórica resultante de la audiencia de la miniserie JK, vehiculada por la Red Globo en enero de 2006. Enfocamos aspectos inherentes a las fuentes de investigación históricas especialmente en lo que se refiere a las producciones audiovisuales, bien como de elementos constitutivos de la producción de una miniserie de temática nacional basada en acontecimientos históricos, destacando la problemática inherente al guión ficcional. Hubo interés en comprender si la ficción basada en la historia influía en la constitución de la memoria sobre el acontecimiento en académicos que, por actuar en las áreas del conocimiento que involucran la comunicación y la historia, presentaban un cierto conjunto de conocimientos específicos.

Palabra-llave: comunicación; miniserie JK; memoria.

\footnotetext{
${ }^{1}$ Doutora em Comunicação pela PUCRS, professora e pesquisadora da FEEVALE/RS, nas áreas de Comunicação e História. E-mail: (ppuhl@feevale.br).

${ }^{2}$ Doutora em História pela PUCRS. Professora e pesquisadora FEEVALE/RS, nas áreas de História e Comunicação. E-mail: (crisennes@feevale.br).
} 


\section{A memória e os produtos audiovisuais}

Este estudo é parte integrante de um projeto de pesquisa que se propõem analisar o lazer através de diferentes abordagens, tendo como eixo central a relação entre a Comunicação e a História. ${ }^{3}$ Neste artigo, enfocamos a relação entre a ficção e os acontecimentos históricos presentes em uma minissérie de produção e temática nacional, visando analisar a construção da memória, de um acontecimento histórico, baseado no roteiro ficcional da minissérie.

Para tanto, num primeiro momento apresentamos questões pertinentes a fontes históricas, ficção e memória. Posteriormente identificamos a minissérie JK como fonte de estudo e, analisamos, a partir de dados empíricos, a hipótese de que uma minissérie baseada em acontecimentos históricos mesmo que, tendo um roteiro ficcional que por isso não tem compromisso com a "verdade”, contribui para a construção de uma memória acerca do processo histórico que se configura, para o público expectador, como a representação do passado, ou seja, como a expressão da “verdade” dos fatos.

Partindo dos objetivos que destacamos para esse estudo, parece-nos essencial abordar a problemática da explicação histórica referente à própria forma de analisar os acontecimentos, ou seja, as fontes históricas.

As fontes históricas são instrumentos de trabalho de um historiador, independente do momento em que vive ou mesmo da escolha teórica que faz para analisar o conjunto de informações que dispõem. Ele necessita de fontes que lhe indique de que maneira aquele acontecimento se processou. A abordagem que o pesquisador de história optará, o método, a técnica, etc., são elementos que podem variar segundo um ilimitado conjunto de componentes de análise, entretanto, sempre será necessário a utilização de fontes para que o fazer histórico se dê. Ao longo do tempo, principalmente após o surgimento da Nova História a abordagem, o tratamento ou mesmo a utilização dada às fontes foi sofrendo transformações, da mesma forma que a concepção do que era considerado como fonte foi sendo ampliado. Novas temáticas se impuseram como objeto de pesquisa e conseqüentemente uma gama de fontes, antes desconsideradas, passou a figurar como privilegiadas para o estudo como, por exemplo, as fontes

\footnotetext{
${ }^{3}$ A partir de 2004 deu-se a aproximação entre os pesquisadores dos grupos de comunicação e de história do Centro Universitário Feevale, sendo que desxencadeou-se um processo de elaboração e execução de projetos envolvendo as duas áreas do conhecimento. No caso específico desse estudo, o projeto que abriga a temática intitula-se "O doce nada fazer: Um estudo sobre o lazer e identidades em Novo Hamburgo”desenvolvido desde 2006 pelas autoras.
} 
audiovisuais, bem como as músicas que têm despertado o interesse de diversos pesquisadores de diferentes campos do conhecimento. Vivemos um contexto onde as imagens, no sentido de produções que envolvem a criação ou reprodução de cenas, sejam elas reais ou ficcionais, fazem parte do cotidiano de todas as pessoas, não sendo, portanto, estranho que os pesquisadores da área da história tenham se ocupado delas com um interesse crescente.

Através dos meios de comunicação, como, por exemplo, a televisão e o cinema, os cidadãos ditos comuns recebem diariamente diversas informações, imagens e sons, sendo que muitos deles são de caráter documental ou se propõem a retratar a vida e as ações de personagens históricos. Estes muitas vezes são percebidos pelos espectadores como testemunhos da verdade, pois ao atingirem o indivíduo em seu espaço próprio ou mesmo em sua situação de lazer, encontram-no receptivo a informação recebida e conferem um tom de verdade ao elemento apresentado, segundo Napolitano (2005) “[...] todas as imagens e sons obtidos pelo registro técnico do real criam um 'efeito de realidade’ imediato sobre o observador.” (p.236).

No caso específico da televisão o autor situa as produções num patamar onde o espectador estabelece um pacto com o que está prestes a observar, estando, por sua vez, suscetível a aceitar as imagens e sons como representação fidedigna da verdade.

Contudo, para o historiador, mais importante do que considerar se as imagens apresentadas correspondem com exatidão aos acontecimentos históricos, é analisar o contexto em que a obra foi produzida e compreender as motivações que levaram uma determinada obra a ter sido produzida em um tempo histórico definido, ou ainda de verificar de que forma é constituída a memória, a partir da ficção, baseando-se na relação entre os acontecimentos históricos e ficção.

Partindo destes pressupostos, nesse artigo, interessa-nos analisar como a memória se construiu a partir da assistência de uma obra ficcional, no caso uma minissérie, baseada em um processo histórico, para tanto, recorremos a conceituação acerca de memória apresentada por Le Goff (1996), na medida em que entendemos, “a memória, como propriedade de conservar certas informações, remete-nos em primeiro lugar a um conjunto de funções psíquicas, graças às quais o homem pode atualizar impressões ou informações passadas, ou que ele representa como passadas” (p. 423) 
Da mesma forma nos reportamos a Halbwachs (2006) ao concordarmos com a perspectiva de que "Nossas lembranças permanecem coletivas e nos são lembradas por outros, ainda que se trate de eventos em que somente nós estivemos envolvidos e objetos que somente nós vimos. Isto acontece porque jamais estamos sós. [...]” (p.30). Assim, a questão que envolve a opção pelas explicações acerca da memória coletiva destacam-se quando o autor indica que os indivíduos não só, possuem lembranças em comum, como também, os ‘outros’ nos auxiliam na rememoração dos acontecimentos, pois,

[...] para melhor me recordar, eu me volto para elas, por um instante adoto seu ponto de vista, entro em seu grupo, do qual continuo a fazer parte, pois experimento ainda sua influência e encontro em mim muitas das idéias e maneiras de pensar a que não me teria elevado sozinho, pelas quais permaneço em contato com elas. (Halbwachs, 2006, p. 31).

Desta forma, entendemos que, os indivíduos que se constituem como agentes focos de nossa pesquisa vivenciaram experiências que lhes conferiram um conjunto particular de memórias que são intrínsecas ao grupo de pertencimento daquele momento e por ainda 'entenderem-se' como indivíduos pertencentes a este grupo conseguem evocar as lembranças do vivenciado, sendo que, para que isso ocorra, conforme Halbwachs (2006), “[...] é preciso que ela não tenha deixado de concordar com as memórias deles e que existam muitos pontos de contato entre uma e outras para que a lembrança que nos fazem recordar venha a ser reconstruída sobre uma base comum. [...]” (p.39). No contexto de nossos estudos, observamos a ligação existente com o grupo através da perspectiva de que estes indivíduos têm em comum o interesse e a dedicação acadêmica na área do conhecimento histórico ou na área da comunicação.

Neste sentido, entendemos que o recordado representa uma seleção feita pelo entrevistado a partir de suas trajetórias de vidas, experiências, representações, etc. Não nos preocupa aqui analisar se os dados obtidos se encontram em concordância com as intenções do roteiro ou mesmo com a veracidade dos acontecimentos apresentados nas documentações históricas. Buscamos, tão somente, identificar que acontecimentos se destacaram como relevantes para nosso público alvo a ponto de merecerem destaque especial em suas recordações.

Assim, nossa opção pela história oral e a utilização desse critério para a análise se fazem porque cremos que ela permite que se recrie a multiplicidade de pontos de 
vista de um passado complexo e multifacetado. Nesse sentido, baseamos nossa interpretação em Thompson (1988), enfocando a história oral como parte integrante e “reveladora” das experiências e memórias, coletivas e individuais, entendida como metodologia de pesquisa que possibilita o resgate, não só de fatos e acontecimentos, mas também de sonhos, esperanças e silêncios.

\section{A produção das minisséries e os acontecimentos históricos}

Na teledramaturgia televisiva, com enfoque nas minisséries, verificamos que as histórias são baseadas, muitas vezes, em acontecimentos históricos, no entanto, os produtores dessas obras, geralmente, procuram se abster da responsabilidade de colocar os fatos como eles aconteceram no tempo histórico. Freqüentemente, os produtores alegam que o objetivo das minisséries é com a ficção, mesmo quando estas transpõem uma época para a tela que conhecíamos dos livros de história.

A busca de definição do termo "ficção" remete ao verbo que originou tal designação. De acordo com Davis (apud LOBO, 2000, p.30) o verbo latino fingere, que originou a palavra ficção, significa "formar”, “moldar” ou "fingir”, e passou a ser muito difundido em inglês para indicar a ação de modelar ou formar um objeto, combinada com a idéia de fingimento e dissimulação.

A distinção entre o real e o ficcional pode ser encontrada nos estudos de Williams (apud LOBO, 2000), para quem o real está ligado ao factual. A referência ao real indica que alguém realizou um fato, enquanto na ficção o acontecimento foi pensado, imaginado e transcrito. Um exemplo são as diferenças entre o trabalho científico e a fantasia.

Assinale-se que há uma grande tendência de incluir a realidade nas obras de ficção. Isto se deve ao ponto-de-vista da recepção, pois as pessoas possuem o hábito de recolocar a ficção, mesmo que esta pertença a uma realidade histórica distante, no mundo vivido delas, “criando um paradoxo na obra de ficção que é julgada pelas suas verdades reais.” (WILLIAMS apud LOBO, 2000, p.31)

A recepção das histórias que compõem as minisséries está relacionada ao formato que este gênero utiliza. Para Lobo (2000) a minissérie no Brasil, também conhecida como seriado é similar à forma mais destacada da televisão norte-americana. Trata-se de uma narrativa segmentada, episódio por episódio, que está sempre 
orientando o telespectador, mesmo que este tenha deixado de assistir a um episódio. Sua finalidade principal é manter o público sempre curioso para assistir diariamente a série.

Pallottini (1998) explica que a minissérie é uma espécie de telenovela curta, escrita antes mesmo de as gravações iniciarem. É uma obra fechada que se define pelos fatos ocorridos, pelas peripécias das personagens e pelo seu final.

Já para Balogh (2002) as minisséries são um produto diferenciado dentro dos formatos ficcionais da TV. Características como o horário de veiculação e o público para o qual elas são destinadas, colaboram para que seja feita uma produção mais elaborada em relação às séries e novelas e que os índices de audiência não sejam cruciais para o desenvolvimento e continuação da obra.

As minisséries por possuírem as características citadas acima como serem menos esquemáticas que as demais obras ficcionais da televisão e terem uma estrutura praticamente pronta antes de ir ao ar, elas podem se tornar "um espaço para testar os limites do televisual e enfrentar o desafio de inovar a linguagem ou de ultrapassar as próprias servidões da linguagem televisual” (BALOGH 2002, p. 127)

As questões referentes à autoria são facilitadas, pois ao contrário das telenovelas, que são construídas em consonância com as reações do público, as minisséries começam a ser veiculadas quase prontas, colaborando para que se tenha uma unidade estrutural do texto, que, por conseqüência, consegue exercer a função poética da linguagem, não sendo necessário, de acordo com a autora, de seguir a estética da repetição, que caracteriza a maioria das séries ficcionais da televisão. Balogh (2002) salienta que cada bloco deve estar conectado com os temas de base da minissérie como um todo. É preciso que os capítulos sigam um fio condutor seja através das personagens ou das ações, para que o telespectador continue a acompanhar a trama nos próximos dias.

Seguindo o pensamento de Balogh (2002) verificamos que o formato adotado pelas minisséries colabora para que sejam abordados assuntos mais densos como adaptações de romances, biografias, acontecimentos históricos, etc..,ou seja, diferente das telenovelas que necessitam que os conflitos sejam resolvidos de forma mais rápida e objetiva para que outro comece a ser construído. 


\section{Ficção e história: a minissérie JK}

A minissérie JK foi exibida pela Rede Globo de 3 de Janeiro a 24 de Março de 2006, com 44 capítulos, veiculada após o Jornal da Globo. A obra foi baseada na vida de Juscelino Kubitschek, que foi presidente do Brasil no período de (1956-1961) e é visto até hoje com os principais responsáveis pelo desenvolvimento econômico brasileiro. Maria Adelaide Amaral, uma das principais autoras da minissérie, durante um ano e meio, viajou pelo Brasil e Portugal, onde o presidente ficou exilado durante a ditadura, para pesquisas e entrevistas que a ajudassem a recriar o personagem.

A autora em entrevista concedia a Revista Época, em dezessete de outubro de 2005, ${ }^{4}$ salienta que seu objetivo era mostrar na televisão o homem que até hoje tem seu nome ligado ao sonho brasileiro de desenvolvimento, “JK conseguiu isso porque foi um político com extrema habilidade de negociação e convencimento. A modernização que ele impôs resultou em problemas tanto com a esquerda quanto com a direita, e ele sempre conseguiu driblá-los”, diz Maria Adelaide em entrevista concedida a repórter Martha Mendonça.

A obra retratou a trajetória de Juscelino a começar pela infância ainda em Minas Gerais, perpassando pela sua formação como médico e o encontro com Sarah. São feitas referências ao seu apogeu político ainda em Belo Horizonte. ${ }^{5}$

A segunda fase esteve centrada na ascensão política de Juscelino até a sua chegada a presidência e a construção de Brasília, destacando o desenvolvimento econômico da sociedade brasileira, que vivenciou os anos dourados, tema que já fora aproveitado para outras minisséries, intitulada de Anos Dourados de 1985.

Os locais das gravações foram divididos entre os estúdios e ambientes externos criados no Projac (Rio de Janeiro) e também contou com cenas externas gravadas na cidade mineira de Tiradentes. Foram 32 dias e 140 cenas, algumas delas foram feitas nas ruas do centro histórico de Santos, e também em Belo Horizonte. Foi usada a computação gráfica para reproduzir alguns fatos como a construção de Brasília, a comemoração da posse do cargo de presidente no Rio de Janeiro, possibilitando mais veracidade às ações.

No entanto essas questões relacionadas a verossimilhança que faz parte da produção das minisséries, principalmente, as ligadas aos acontecimentos históricos, fazem com que a

\footnotetext{
${ }^{4}$ MENDONÇA, Martha. O JK real e a lenda. Revista Época. Dados retirados da reportagem JK real e lenda. Disponível em: http://revistaepoca.globo.com/Epoca/0,6993,EPT1052813-16662,00.html. Acesso em: 26 de maio 2007.

${ }^{5}$ Informações adaptadas pela autora do site (http://jk.globo.com/Series/JK/0,,5083,00.html).

Acesso em 27 de maio de 2007.
} 
Imprensa tenha diversos posicionamentos, como foi o caso da reportagem intitulada, Procura-se Juscelino Kubitschek de Oliveira, escrita pelo poeta Urariano Mota e publicada site Observatório da Imprensa ${ }^{6}$, em nove de janeiro de 2006, logo após o início da minissérie, em resposta a entrevista concedida por Maria Adelaide Amaral para a Revista Época. ${ }^{7}$

Urariano (2006) reflete sobre o compromisso que os escritores de roteiros deveriam ter com a veracidade dos fatos ao produzir uma obra biográficas para a televisão aberta. O poeta critica a posição de Maria Adelaide quando esta citou que "minissérie não é documentário” na reportagem da Revista Época, ${ }^{8}$ no seguinte trecho da sua coluna:

[...] uma defesa para possíveis críticas de testemunhas e testemunhos e historiadores à liberdade de autor, que, reconheçamos, é um princípio inegociável. Ainda que se confunda liberdade com liberdades, ou leviandades, mais vale a liberdade de que se abusa que o abuso da sua extinção. No entanto, aqui, na minissérie JK, é o espaço onde se invoca um princípio geral de criadores para legitimar um abuso contra a liberdade de criação.

Alberto Dines, também no site do Observatório da Imprensa na matéria chamada Estratégia para a falta de notícias - JK, a musa do verão9, publicada também em nove de janeiro de 2006, salienta a falta de notícias naquele período e o destaque para a minissérie nos principais jornais e revistas. Dines (2006) critica a exaltação da personalidade de JK e a preocupação com a sua vida sexual, e diz que no Brasil só ficamos sabendo dos fatos históricos pela tradução da televisão, e acredita que em breve começariam as especulações do uso de acontecimentos históricos em JK (já que faziam poucos dias do início da minissérie).

A exploração de períodos e acontecimentos históricos para a construção de minisséries é uma constatação que é atualizada a cada temporada, neste ano de 2007, o

\footnotetext{
${ }^{6}$ MOTA, Urariano. Procura-se Juscelino Kubitschek de Oliveira. Observatório da Imprensa. Disponível em: http://observatorio.ultimosegundo.ig.com.br/artigos.asp?cod=363TVQ002. Acesso em: 26 de maio 2007.

${ }^{7}$ Informações adaptadas pela autora do site (http://jk.globo.com/Series/JK/0,,5083,00.html). Acesso em 27 de maio de 2007.

${ }^{8}$ Informações adaptadas pela autora do site (http://jk.globo.com/Series/JK/0,,5083,00.html). Acesso em 27 de maio de 2007.

${ }^{9}$ DINES, Alberto. Estratégia para a falta de notícias - JK a musa do verão. Observatório da Imprensa. Disponível em: http://observatorio.ultimosegundo.ig.com.br/artigos.asp?cod=363TVQ001. Acesso em: 26 de maio 2007.
} 
fato histórico recente escolhido foi a história da independência do Acre e o ciclo da borracha, para isso personagens como Galvez e Chico Mendes foram retratados, na obra chamada Amazônia escrita por Glória Perez.

Segundo Kornis (2001) essa prática iniciou na televisão brasileira a partir de 1986, pós-regime militar, e desde então a Rede Globo vem se constituindo como uma importante agente de construção de uma identidade nacional, não só pela amplitude de sua rede, mas também pelos temas abordados pela sua programação ficcional, entre eles a representação da história brasileira recente, como o caso de JK.

Balogh (2002, p.134) acrescenta que existe um cuidado extremo com o uso da linguagem e com a escolha de recursos técnicos expressivos adequados. Enfatiza igualmente que as minisséries funcionam como "painéis de uma época, pinturas em movimento”, e cita obras como Anos Dourados (1986) e Anos Rebeldes (1992), que foram produzidos pela Rede Globo. Segundo a pesquisadora, as minisséries, mesmo contendo tramas ficcionais, colaboram para levar ao público, acontecimentos que fizeram parte da trajetória histórica da sociedade brasileira.

Surge dessa problemática o impulso para desenvolvermos a pesquisa, a fm de refletirmos sobre esta temática que se torna atual a cada minissérie que é produzida e veiculada na televisão.

Baseado nessa discussão, este artigo, busca identificar e analisar a construção de uma memória histórica no público universitário da Feevale decorrente da audiência da minissérie JK. Este estudo constitui-se em uma das fases de um projeto de maior amplitude que tem por temática central as relações entre história e meios audiovisuais, sendo, portanto um olhar pontual e apresentando por essa razão resultados parciais em relação ao todo.

Objetivando identificar e analisar a memória resultante da audiência freqüente da minissérie JK, nesta fase da pesquisa, optamos pela realização de uma abordagem qualitativa da temática, elencando como público alvo os acadêmicos do Curso de História e do Curso de Comunicação Social, habilitação Jornalismo, regularmente matriculados na Feevale no segundo semestre de 2006.

A delimitação do público alvo da pesquisa se justifica na medida em que estes indivíduos desenvolvem suas atividades acadêmicas e de aprofundamento teórico em cursos que têm por meta discutir tanto no campo da produção televisiva e a sua 
qualidade, no caso do Jornalismo, quanto ao que se refere aos processos históricos e sua utilização pela mídia, preocupação latente da área da História.

No Curso de Comunicação, habilitação Jornalismo foram escolhidos os acadêmicos das disciplinas que abordam a produção televisiva, são elas: Telejornalismo I (quinto semestre) e Telecinejornalismo (sexto semestre), totalizando 22 acadêmicos respondentes. Já no Curso de História a seleção do público alvo centrou-se nos acadêmicos que nos dois últimos semestres cursaram disciplinas relacionadas à trajetória histórica brasileira do século XX, totalizando 42 acadêmicos. ${ }^{10}$

Para a coleta dos dados optamos pela construção de uma entrevista estruturada que mesclou questões fechadas de múltiplas escolhas tanto avaliativas, quanto de mostruário, com questões abertas de caráter argumentativo. O instrumento de pesquisa foi estruturado a partir dos objetivos propostos por nosso estudo, para tanto, visamos identificar o perfil dos entrevistados, pontuar suas noções gerais acerca dos processos históricos do período e dos elementos constitutivos de uma minissérie, bem como, identificar a memória resultante a partir da audiência da minissérie.

Para avaliar o perfil dos acadêmicos respondentes foram feitas as seguintes questões ${ }^{11}$ :

1. Idade:

Sexo: ( ) Feminino ( ) Masculino

2. Curso: Semestre: Média de disciplinas por semestre:

3. Nível acadêmico:

a. ( ) graduação ( ) pós-graduação.

4. Modalidade de ensino médio:

a. ( ) particular. (...) estadual ( ) municipal ( ) supletivo ( ) outro. Qual?

5. Trabalha durante o dia?

a. ( ) não ( ) sim. Média diária de horas no trabalho:

6. Seu trabalho está relacionado com sua área de formação?

a. ( ) Não ( ) Sim.

7. Cidade da residência: Você mora?

a. ( ) sozinho ( ) pais ( ) companheiro (a) ( ) filhos. Quantos? Idades?

8. Com que freqüência assiste TV?
a. ( ) Não assisto
b. ( ) 1 a 2 horas diárias.
c. ( ) 3 a 4 horas diárias.
d. ( ) Mais de 5 horas
e. ( ) Eventualmente. Média de dias da semana:
f. ( ) Raramente. Justifique:

\footnotetext{
${ }^{10}$ A pesquisa foi aplicada em setembro de 2006.

${ }^{11}$ As questões que serão apresentadas a partir deste item estavam todas em um mesmo documento, quando aplicadas pelas pesquisadoras, porém optamos em separá-las no artigo para melhor compreensão da análise.
} 
9. Você assistiu a minissérie JK transmitida pela Rede Globo?
a. ( ) Não. Por quê?
b. ( ) Sim. Por quê?

OBSERVAÇ̃̃O: Se você respondeu SIM passe para a questão: 12 Se você respondeu NÃO responda as questões: 10 e 11.

Identificamos que o perfil do público alvo, a partir dos acadêmicos entrevistados, a maioria pertencia ao sexo feminino em uma faixa etária com predominância entre 20 e 30 anos. A maior parte dos entrevistados possuíam atividades profissionais durante o dia em uma média de oito horas e dedicavam-se as atividades acadêmicas numa média de 3 a 4 noites semanais. Observou-se igualmente que em torno de $80 \%$ dos entrevistados tinham por hábito dedicarem-se a atividade de assistir televisão num período de, no máximo, duas horas diárias.

A análise dos dados identificatórios de perfil dos entrevistados e com cruzamento das informações (retiradas das questões referentes ao campo pessoal e profissional) pudemos inferir que mesmo estando ocupados com atividades na esfera profissional, familiar e pessoal na maior parte do dia, havia possibilidade deste grupo ter assistido a minissérie sobre JK, uma vez que esta teve como horário de transmissão às 23 horas e que 50\% dos entrevistados residiam na mesma cidade onde se localiza a instituição de ensino que freqüentam e, por conseqüência, mesmo nos dias em que tinham aula, já estavam em casa na hora da transmissão da minissérie.

Contudo, o resultado da pesquisa trouxe como dado negador dessa hipótese. A percepção de que apenas 30\% dos entrevistados foram telespectadores assíduos da minissérie JK, sendo que os 70\% restantes identificaram a incompatibilidade de horário, a necessidade de acordar cedo no outro dia e a falta de tempo como fatores limitadores dessa atividade.

Por outro lado, mesmo não assistindo a minissérie os acadêmicos que ouviram comentários sobre ela ao serem questionados sobre a validade da produção de programas desse gênero, foram unânimes em manifestar a aprovação e indicar as minisséries como propagadoras de cultura para a sociedade. Esse dado foi verificado através das respostas dadas às seguintes questões:

10. Apesar de não ter assistido a minissérie ouviu ou leu comentários sobre ela?

a. ( ) Não. Sua participação nessa entrevista foi fundamental para a pesquisa. Agradecemos sua participação e nos colocamos a disposição para esclarecimento. Obrigada.

b. ( ) Sim.(ir para a questão 11)

11. Para os colaboradores que responderam sim na questão anterior (Questão 10)

a. Que tipo de opiniões você ouviu ou leu a respeito da minissérie?

b. Você julga ser importante a execução de produções audiovisuais que utilizem acontecimentos históricos em seus roteiros? 


$$
\begin{aligned}
& \text { i. ( ) Não. Por quê? } \\
& \text { ii. ( ) Sim. Por quê?? }
\end{aligned}
$$

A seguir um quadro mais detalhado referente ao número de estudantes que assistiram ou não a minissérie; os resultados foram os seguintes ${ }^{12}$ :

\begin{tabular}{|l|l|l|}
\hline Acadêmicos & \multicolumn{1}{|c|}{ Assistiram } & Não Assistiram \\
\hline Jornalismo & 6 & 16 \\
\hline História & 13 & 28 \\
\hline TOTAL & 19 & 44 \\
\hline
\end{tabular}

Na avaliação mais de $90 \%$ dos alunos que assistiram a minissérie, tanto do curso de Comunicação quanto os da História, a produção foi apontada como tendo um desempenho muito bom em relação a qualidade da produção, a atuação do elenco e a divisão da estrutura dos capítulos. A discordância de opiniões na avaliação deu-se nos itens referentes ao roteiro ficcional e a exatidão da minissérie quanto à trajetória histórica, observando-se que quanto ao roteiro foram precisamente os alunos de comunicação que atribuíram o juízo de valor ruim e os alunos do curso de história que mencionaram os problemas quanto a exatidão histórica. Neste caso, por se tratar da opinião de um número reduzido de entrevistados podemos inferir que as opiniões sejam resultantes de um exacerbado rigor quanto às questões ligadas as suas áreas de formação.

As questões que colaboraram para as constatações acima são as seguintes:

12. Com que freqüência você assistiu a minissérie?
a. ( ) Todos os dias.
b. ( ) 1 a 2 vezes por semana
c. ( ) 3 a 4 vezes por semana

13. Que avaliação você faz a respeito dos seguintes itens:
a. Qualidade da produção (cenários, figurino, fotografia, iluminação, som etc.):
( ) Ruim ( ) Bom ( ) Muito bom ( ) Excelente ( ) Não sei ou não posso opinar.
b. Escolha e atuação do elenco:
( ) Ruim ( ) Bom ( ) Muito bom ( ) Excelente ( ) Não sei ou não posso opinar.
c. Roteiro ficcional:
( ) Ruim ( ) Bom ( ) Muito bom ( ) Excelente ( ) Não sei ou não posso opinar.
d. Exatidão histórica:
( ) Ruim ( ) Bom ( ) Muito bom ( ) Excelente ( ) Não sei ou não posso opinar.
e. Duração:
( ) Ruim ( ) Bom ( ) Muito bom ( ) Excelente ( ) Não sei ou não posso opinar.

\footnotetext{
${ }^{12}$ Ao todo foram 64 acadêmicos entre ambos os Cursos, porém um entrevistado não respondeu a questão referente a ter assistido ou não a minissérie.
} 
Para observarmos a constituição da memória a partir da audiência da minissérie foram feitas as questões abaixo:

14. Destaque os três momentos ou acontecimentos apresentados na minissérie JK que em sua opinião foram os mais significativos, favor colocar em ordem de preferência;

a.

b.

c.

Após a leitura das respostas optamos, para esse estudo, em estabelecer categorias que contribuíssem para a compreensão dos dados da entrevista, neste sentido e a partir das ocorrências estabelecemos três eixos de categorias, sendo que o primeiro referia-se a JK e seus feitos políticos, o segundo JK e sua trajetória histórica e por fim JK e a sua contribuição sociedade. Através desta categorização obtivemos os seguintes resultados:

\begin{tabular}{|l|l|l|l|l|l|}
\hline \multicolumn{1}{|c|}{ Feitos políticos } & & \multicolumn{1}{c|}{ Trajetória histórica } & & \multicolumn{1}{c|}{ Sociedade } & \\
\hline Construção de Brasília & 9 & Infância difícil de JK & 3 & Vida cultural & 1 \\
\hline Eleição e presidência & 3 & Casamento & 2 & Influência estrangeira & 1 \\
\hline Morte de JK & 3 & Sara K & 1 & Influência da imprensa & 1 \\
\hline Voto a cabresto & 2 & Formatura & 1 & & \\
\hline Jogos políticos & 2 & Dificuldades do exílio & 1 & & \\
\hline Populismo & 2 & Morte do pai de JK & 1 & & \\
\hline Ideais políticos & 2 & Amor filha adotiva & 1 & & \\
\hline
\end{tabular}

A partir da análise do quadro observamos uma predominância de aspectos relacionados aos acontecimentos políticos presentes no período retratado pela minissérie. No tocante aos feitos políticos de JK, devido ao enfoque direcionador da produção, a criação de Brasília e a conseqüente transferência do centro de poder do país representou a memória mais recorrente, entretanto as questões como o voto a cabresto e a relação estabelecida com a população também foram destacados pelos entrevistados. No que é referenciado a morte de JK a justificada dado pelos entrevistados está na desconfiança de um complô político que o queria fora do poder.

Já sobre a trajetória histórica de JK, os principais destaques situaram-se nas dificuldades vivenciadas pelo presidente, desde sua infância até os aspectos relacionados com o período no exílio. Neste sentido, a minissérie parece ter produzido uma empatia com o público telespectador que passou a percebe no político uma pessoa com problemas com os quais foi possível estabelecer uma identificação. Há uma desmistificação do endeusamento da figura do líder ao sobressair-se o homem e as suas relações e interações com o meio. 
Por fim, ainda foram apontados aspectos relacionados a sociedade, sendo que estes em menor ocorrência numérica e sem o destaque dado aos elementos que envolviam JK. Neste sentido, podemos considerar que a minissérie ao centrar o roteiro no personagem utilizou a sociedade apenas como cenário, onde as ações eram representadas. Não houve, pelo menos aparentemente, uma preocupação em enfocar a conjuntura da sociedade como aspecto fundamental para o processo histórico do período.

De um modo geral podemos considerar que para o público alvo da nossa pesquisa, as memórias mais significativas se situaram entorno da figura carismática de JK, sendo que mesmo aquelas que poderiam apresentar uma conotação negativa, como a questão do voto a cabresto, não foram destacadas como aspecto que desonerasse a figura do líder político.

A partir destas inferências percebemos que o texto audiovisual possui mecanismos que corroboram com a interpretação do sujeito de forma direta, permitindo a manifestação dos seus sentimentos e conhecimentos prévios. Por isso, Nova (1996) sugere que antes de uma leitura visual dos acontecimentos históricos é preciso uma leitura histórica, a fim de buscar as verossimilhanças existentes na obra escolhida, para não nos deixarmos persuadir pelas armadilhas textuais propostas pelos textos ficcionais. É importante salientar que a escolha de critérios é indispensável, para que seja possível apreender a concepção histórica e visualizar os anacronismos presentes na obra.

A autora também recomenda que seja feita uma comparação entre os elementos retirados do filme com os acontecimentos históricos baseados nas fontes históricas, para assim verificar o novo apresentado pela ficção, pois dessa forma estaremos formulando um novo sentido histórico entre o passado e o presente, mediado pelas imagens em movimento, como a televisão e outros produtos audiovisuais, que são hoje poderosos instrumentos divulgadores dos acontecimentos históricos.

Por outro lado, a partir de diversos autores abordados nesse artigo, foi constatado que a ficção não possui o intuito de representar a verdade, mas de qualquer forma, ela colabora com a constituição da memória dos acontecimentos históricos, de acordo com a pesquisa realizada com os acadêmicos do Curso de História e da habilitação de Jornalismo da Feevale. É importante destacar que os respondentes representam um recorte limitado, um público universitário diferenciado, mas que 
serviram para verificar que através das minisséries é possível ter subsídios que podem direcionar o entendimento de fatos históricos.

Estes por estarem incluídos em uma obra ficcional acabam sendo romanceados, ligados ao bem ou ao mal e carregados de juízos de valor, assim é provável que o entendimento seja prejudicado, mas para que isso não ocorra, cabe ao telespectador buscar outras fontes para compreender o acontecimento histórico sob outros testemunhos, seja pela Imprensa, pelos livros de História, etc..

A escolha dos acadêmicos universitários de ambos os cursos, além de serem considerados telespectadores em potencial, de acordo com o horário e temática da minissérie, em breve serão agentes/colaboradores da construção da memória. Os jornalistas, quando exercerem funções ligadas às produções audiovisuais ou como críticos delas e os historiadores como tradutores e/ou estudiosos das minisséries como fontes históricas para compreensão seja do momento passado ou do atual no qual a minissérie está sendo lançada.

Num outro sentido, e, a partir da análise das fontes utilizadas para exemplificar as questões que são suscitadas pela Imprensa, verificamos que os limites para a recriação de acontecimentos históricos para a televisão com o tom romanesco acabam por suscitar diversos debates ligados a verdade histórica, aos limites possíveis e aceitáveis para criação, a finalidade da minissérie ficcional e a forma com que vai sendo constituída a memória histórica, a partir dessas obras ficcionais, principalmente as que são veiculadas em canais abertos e de grande abrangência, como é o caso da Rede Globo e da minissérie JK.

Notamos que a relação entre acontecimentos históricos e a criação artística e estética da obra televisiva, mesmo ao acrescentar conflitos, ocultar algumas informações indispensáveis sob o olhar histórico, contribuem para a disseminação dos conhecimentos históricos para o grande público, porém não deixam claro o limite para a inteligibilidade dos fenômenos históricos. Mas seria essa uma “obrigação” do ficcional ou mesmo sem ser a sua finalidade primeira é necessário que as obras baseadas em acontecimentos históricos tenham a dimensão da sua interferência social na constituição da memória?

Dessa forma, é importante ressaltar que nesse estudo não buscamos “culpar” nem "absolver" as minisséries a partir das conceituações isoladas sobre o que é Ficção 
ou do que é História. A nossa proposta é tentar visualizar as minisséries como objetos potenciais de pesquisa que podem ir além desses conceitos, pois somente assim poderá ser esclarecido as suas influências, as suas representações e os seus significados como fonte histórica para a cultura brasileira.

\section{Referências Bibliográficas}

BALOGH, Anna Maria. O discurso ficcional na TV. São Paulo; Editora da Universidade de São Paulo, 2002.

DINES, Alberto. Estratégia para a falta de notícias JK a musa do verão. Observatório da Imprensa. Disponível em:

//observatorio.ultimosegundo.ig.com.br/artigos.asp?cod=363TVQ001. Acesso em: 26 de maio 2007.

HALBWACHS, Maurice. A memória coletiva. São Paulo: Ed. Centauro, 2006. 222p. KORNIS, Mônica Almeida. Uma memória da história nacional recente: as minisséries da Rede Globo. In: INTERCOM - Sociedade Brasileira de Estudos Interdisciplinares da Comunicação XXIV Congresso Brasileiro da Comunicação, Campo Grande /MS, setembro 2001.

LE GOFF, Jacques. História e memória. Campinas, SP: Unicamp, 1996.

MOTA, Urariano. Procura-se Juscelino Kubitschek de Oliveira. Observatório da Imprensa. Disponível em: http://observatorio.ultimosegundo.ig.com.br/artigos.asp?cod=363TVQ002. Acesso em: 26 de maio 2007.

MENDONÇA, Martha. O JK real e a lenda. Revista Época. Disponível em: http://revistaepoca.globo.com/Epoca/0,6993,EPT1052813-1666-2,00.html. Acesso em: 26 de maio 2007.

LOBO, Narciso. Ficção e Política - o Brasil nas minisséries. Manaus: Valer, 2000.

NAPOLITANO, Marcos. A História depois do papel. In: PINKS, Carla. (org). Fontes Históricas. São Paulo: Contexto, 2005. p. 235/290.

NOVA, Cristiane. O Cinema e o Conhecimento da História. In: O Olho da História: revista de história contemporânea. Salvador, v.2, n. 3. 1996.

PALLOTTINI, Renata. Dramaturgia de televisão. São Paulo, Editora Moderna, 1998. PINKS, Carla. (org). Fontes Históricas. São Paulo: Contexto, 2005.

THOMPSON, Paul. A Voz do Passado. História Oral. 2. ed. São Paulo: Paz e Terra, 1988; 